\title{
Dirençli Epilepsinin Tedavi Edilebilir Bir Nedeni: Piridoksin Bağımlı Epilepsi
}

\section{A Treatable Cause of Refractory Epilepsy: Pyridoxine-Dependent Epilepsy}

Hepsen Mine SERIN¹, Sanem YILMAZ', Erdem ŞiMŞEK', Seda KANMAZ', Ayça AYKUT²,

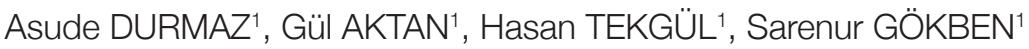

${ }^{1}$ Ege Üniversitesi Tıp Fakültesi Çocuk Sağlı̆̆ı ve Hastalıkları Anabilim Dalı, Çocuk Nöroloji Bilim Dalı, İzmir, Türkiye

²Ee Üniversitesi Tıp Fakültesi Tıbbi Genetik Anabilim Dalı, İzmir,Türkiye

\section{Öz}

Amaç: Piridoksin bağımlı epilepsi, tipik olarak bebeklik veya erken çocukluk döneminde inatçı nöbetler ile seyreden nadir görülen otozomal resesif bir hastalıktır. Nöbetler geleneksel antiepileptik tedavilere dirençli olup, farmakolojik dozda piridoksine yanıt verir. Bu çalışmada Piridoksin Bağımlı Epilepsi (PBE) tanısı ile izlediğimiz altı hastanın klinik ve genetik Özelliklerini sunmayı amaçladık.

Gereç ve Yöntemler: Çocuk Nöroloji Bilim Dalı'nda piridoksin bağımlı epilepsi tanısı ile izlenen altı olgunun klinik ve genetik özellikleri ile prognozu retrospektif olarak değerlendirildi.

Bulgular: Çalışmaya alınan hastaların 5'i erkek, 1'i kız olup, yaş ortalaması $6.83 \pm 3.71$ yıldı. Nöbet başlangıç yaşı ortalama 22.33 \pm 31.77 (3-90 gün) olup, bir hasta (n:4) hariç diğerleri yenidoğan döneminde başlamıştı. Üç hastada fokal motor nöbet, 2 hastada jeneralize motor nöbet ve 1 hastada epileptik spazm izlendi. Hastaların vitamin B6 tedavisi bir hasta hariç erken dönemde bașlandı. Erken dönem tedavi bașlanan bir hasta dışında diğer hastalarda mental retardasyon, stereotipik hareketler ve otistik bulgular izlendi. Yapılan moleküler genetik analizde 5 farklı mutasyon saptanmıştır [2 olguda homozigot c.1597delG (p.Ala533ProfsTer18), 1 olguda homozigot c.781 A>G (p.Met261Val),1 olguda birleşik heterozigot c.328C>T (p.Arg110Ter)/c.1566-1G>T, 1 olguda heterozigot c.328C>T (p.Arg110Ter) ve 1 olguda heterozigot c.1356 A>C (p.Lys452Asn)].

Sonuç: Piridoksin Bağımlı Epilepsi tedavi edilebilir epilepsi nedenlerinden biri olup açıklanamayan dirençli nöbetleri olan bebeklerde mutlaka düşünülmeli ve terapotik dozda piridoksin tedavisine başlanmalıdır.

Anahtar Kelimeler: Nöbet, Piridoksin bağımlı epilepsi, Vitamin B6

\begin{abstract}
Objective: Pyridoxine-dependent epilepsy (PDE) is a rare autosomal recessive disorder that typically presents with refractory seizures in infancy or early childhood. Seizures are resistant to conventional antiepileptic treatments and responsive to pharmacologic doses of pyridoxine. In this study, we aimed to present the clinical and genetic features of six patients followed up in our clinic with PDE diagnosis.

Material and Methods: Pyridoxine-dependent epilepsy (PDE) is a rare autosomal recessive disorder that typically presents with refractory seizures in infancy or early childhood. Seizures are resistant to conventional antiepileptic treatments and responsive to pharmacologic doses of pyridoxine. In this study, we aimed to present the clinical and genetic features of six patients followed up in our clinic with PDE diagnosis.

Results: Among six patients five were male and one was female. Mean age was $6.83 \pm 3.71$ years. The mean age of onset for seizures was $22.33 \pm 31.77$ (3-90 days). Seizures had started in the newborn period in all patients except one patient (n: 4). Three patients had focal motor seizures, 2 patients had generalized motor seizures and 1 patient had epileptic spasms. Vitamin B6 therapy was started in the early period except one patient. Mental retardation, stereotypic
\end{abstract}

\section{(10)}

:0000-0002-4109-9401 :0000-0002-8719-0665 0000-0002-4413-8779 0000-0002-8738-1242 0000-0002-1460-0053 $0000-0002-4109-9401$ 0000-0002-5367-2236 0000-0002-9972-0651 0000-0001-7896-5716
Çıkar Çatışması / Conflict of Interest: Tüm yazarlar adına, sorumlu yazar çıkar çatışması olmadığını belirtir.

Etik Kurul Onayı / Ethics Committee Approval: Ege Üniversitesi Etik Kurulu'ndan 02.05.2019 tarih ve 19-5T/47 sayı ile onay alınmıştır. Kayıt sırasında veliler tarafından araştırmaya katılım için bilgilendirilmiş bir onay imzalanmıştır.

Yazarların katkısı / Contribution of the Authors: SERIN HP:Tasarım, Makale yazımı, literatür tarama, veri toplama, YILMAZ S:Tasarım, analiz, SiMSEK E: iteratür tarama, veri toplama, KANMAZ S: Literatür tarama, veri toplama, AYKUT A: Makale yazımı, tasarım, DURMAZ A: Analiz, danıșmanlık, AKTAN G: Analiz, danışmanlık ,TEKGÜL H: Danışmanlık, GÖKBEN S: Danışmanlık, denetleme

Atıf yazım şekli / How to cite : Serin HP, Yılmaz S, Şimşek E, Kanmaz S, Aykut A, Durmaz A ve ark. Dirençli Epilepsinin Tedavi Edilebilir Bir Nedeni: Piridoksin Bağımlı Epilepsi Dirençli Epilepsinin Tedavi Edilebilir Bir Nedeni:PBE. Türkiye Çocuk Hast Derg 2020;14:461-464.
Yazışma Adresi / Correspondence Address:

Ege Üniversitesi Tıp Fakültesi Çocuk Sağlığı ve Hastalıkları Anabilim Dalı, Çocuk Nöroloji Bilim Dalı, İmir, Türkiye

E-posta: hepsenmine@yahoo.com
Geliş tarihi / Received : :21.05.2019 Kabul tarihi / Accepted : 18.09.2019 Elektronik yayın tarihi : 13.05 .2020 Online published

DOI: $10.12956 /$ tchd.568456 
movements and autistic findings were observed in the all patients except one patient who had received early treatment. Molecular genetic analysis revealed 5 different mutations [homozygous c.1597delG (p.Ala533ProfsTer18) in 2 cases, homozygous c.781 A> G (p.Met261Val) in 1 case, compound heterozygous c.328C> T (p.Arg110Ter) / c.1566- 1G>T, 1 case heterozygous c.328C> T (p.Arg110Ter) and 1 case heterozygous c.1356 A>C (p.Lys452Asn) ] .

Conclusion: Pyridoxine-dependent epilepsy is a treatable cause of epilepsy and should come to mind in infants with unexplained refractory seizures. Treatment with a therapeutic dose of pyridoxine should be started promptly.

Key Words: Seizure, Pyridoxine-dependent epilepsy, Vitamin B6

\section{GiRiş}

Piridoksin bağımlı epilepsi (PBE) (OMIM \# 266100), geleneksel antiepileptik tedaviye direnç ve B6 vitaminin farmakolojik dozlarına terapötik cevap ile karakterize otozomal resesifepileptik ensefalopatidir (1). İlk olarak 1954'te, tedaviye dirençli nöbetleri olan ve B6 vitamini içeren bir multivitamin kokteyli uygulandıktan sonra nöbetleri duran bir bebekte tanımlanmıştır (1). Altta yatan genetik defekt uzun süre bilinmediğinden PBE tanısı, kontrollü bir piridoksin uygulama ve kesilme denemesinden sonra nöbetlerde remisyon ve nüks görülmesine dayanmaktaydı (2). Prevalans yaklașık olarak 1:276.000 ile1:700.000 arasındadır (3). PBE hastalarında tanımlanan klinik özellikler anormal fetal hareketler, perinatal hipoksik-iskemik hasar, irritabilite, kas tonusu değişiklikleri, solunum sıkıntısı, abdominal distansiyon, hepatomegali, hipotermi, şok ve asidozdur (4). Konvansiyonel olarak tanı için dört klinik kriter gereklidir: Antiepileptik tedaviye dirençli nöbetler, piridoksine iyi yanıt, piridoksin monoterapisinde tam nöbet kontrolü ve piridoksin yoksunluğundan sonra nöbet tekrarı (3).

Piridoksin bağımlı epilepsili hastaların çoğunda bozukluğa, a-aminoadipik semialdehit dehidrojenazın enzim aktivitesindeki eksiklik neden olur (5). Sorumlu gen, lizin katabolizmasının pipekolik asit yolağındaki alfa-aminoadipik semialdehit dehidrojenazı (a-AASA dehidrojenaz) kodlayan antiquitin (ALDH7A1) olup, 5q31.4 kromozomu üzerinde bulunur (6).

Bu çalışmada PBE tanısı ile izlediğimiz altı hastanın klinik ve genetik özelliklerini sunduk.

\section{GEREÇ ve YÖNTEMLER:}

Çalışmaya Çocuk Nöroloji Bilim Dalı'nda PBE tanısı ile izlenen altı hasta alındı. Hastaların dosyalarından demografik verileri, nöbet başlangıç yaşı, nöbet tipi, nörogörüntüleme ve elektroensefalografi (EEG) sonuçları, genetik analizleri, tanı yaşı, tedavileri ve klinik izlemleri kayıt edildi. Bu çalışma için Ege Üniversitesi Etik Kurulu'ndan 02.05.2019 tarih ve 19-5T/47 sayı ile onay alınmıştır.

\section{BULGULAR}

Çalışmaya alınan hastaların 5'i erkek, 1 'i kız olup, yaş ortalaması $6.83 \pm 3.71$ yıldı. İki ailede birinci derece akrabalık öyküsü mevcuttu.
Hastaların hepsi term doğmuş olup, bir hastada mekonyumlu doğum, bir hastada da asfiktik doğum öyküsü vardı. Nöbet

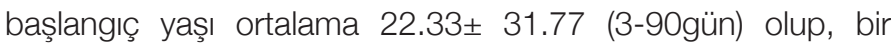
hasta (n:4) hariç diğerleri yenidoğan döneminde başlamıştı. Üç hastada fokal motor nöbet, 2 hastada jeneralize motor nöbet ve 1 hastada spazm tipi nöbet izlendi. Hastaların ilk EEG'si bir hastada (n:3) normal olup, diğerlerinde fokal keskin dalga deşarjları izlendi. Hastaların vitamin B6 tedavisi bir hasta hariç erken dönemde başlanmıştı. Dört numaralı hastanın ateşle tetiklenen nöbetleri olması nedeniyle ön planda Dravet sendromu düşünülmüş, bakılan SCN1A ve SCN1B'de mutasyon saptanmamış, bu süreçte hasta başka merkezlerde takip edilmişti. Son başvurusunda ALDH7A1 gen analizi gönderilmiș ve PBE tanısı konularak vitamin B6 tedavisi 9 yașında bașlanmıștır. Erken dönem tedavi bașlanan bir hasta dıșında diğer hastalarda mental retardasyon, stereotipik hareketler ve otistik bulgular eşlik ediyordu.

Klinik olarak PBE hastalığı öntanısı alan 6 olgunun intravenöz kan örneği alınarak ALDH7A1 (NM_001182.4) geni ile ilgili tüm kodlayıcı ekzonların ve ekzon-intron bileşkelerinin Sanger dizi analiziileyöntemiileanalizleriyapılmıştır. Yapılan molekülergenetik analizde 2 olguda homozigot c.1597delG (p.Ala533ProfsTer18), 1 olguda homozigot c.781 A>G (p.Met261Val), 1 olguda birleşik heterozigot c.328C>T (p.Arg110Ter)/c.1566-1G>T, 1 olguda heterozigot c.328C>T (p.Arg110Ter) ve 1 olguda heterozigot c.1356 A>C (p.Lys452Asn) olmak üzere 5 farklı mutasyon saptanmıştır (Tablo I). Varyant Sınıflandırılması in silico tahminleme algoritmaları (SIFT, PolyPhen, MutationTaster), farklı biyoinformatik veritabanları (ClinVar, dbSNP, HGMD, VarSome) ve ACMG varyant patojenite klasifikasyonu göz önüne alınarak yapılmıştır. Saptanan c.781 A>G (p.Met261Val) ve c.1356 A $>C$ (p.Lys452Asn) mutasyonları literatürde daha önceden tanımlanmamış olup klinik önemi bilinmeyen (VUS) varyant olarak tanımlanmıştır. Hastaların klinik, radyolojik özellikleri ve genetik analizleri Tablo l'de verilmiştir.

\section{TARTIŞMA}

Piridoksin bağımlı epilepsi klasik olarak neonatal dönemde başlayan dirençli nöbetlerle karakterize olup, olguların 1/3'ünde geç başlangıçlı (3 yaşa kadar) nöbetler, otizm, fenobarbital gibi sık kullanılan antiepileptik ilaçlara veya düşük doz piridoksine yanıtı içeren atipik seyir görülebilir. Bu seride, tüm olguların nöbetleri neonatal dönem ya da erken infantil dönemde başlamış olup klasik prezentasyon göstermişlerdir (7). Nöbet tipleri aynı hastada bile değişkendir ve miyoklonik, klonik, 
Tablo I: Hastaların klinik, radyolojik ve genetik özellikleri.

\begin{tabular}{|c|c|c|c|c|c|c|}
\hline & Hasta 1 & Hasta 2 & Hasta 3 & Hasta 4 & Hasta 5 & Hasta 6 \\
\hline Yaş(yıl)/Cinsiyet & $1 / K$ & 11/E & $5 / E$ & 10/E & $4 / E$ & 10/E \\
\hline Akrabalık & var & var & yok & yok & yok & yok \\
\hline Nöbet başlangıcı & 3.gün & 3.gün & 3.gün & 3.ay & 1.ay & 5.gün \\
\hline Nöbet tipi & Fokal motor & $\begin{array}{l}\text { Jeneralize } \\
\text { motor }\end{array}$ & Jeneralize motor & Fokal motor & Spazm & Fokal motor \\
\hline EEG & $\begin{array}{c}\text { Frontoemporal keskin } \\
\text { dalga }\end{array}$ & $\begin{array}{l}\text { Sağ hemisfer } \\
\text { arka bölümlerde } \\
\text { keskin dalga }\end{array}$ & Normal & $\begin{array}{l}\text { Frontal ve arka } \\
\text { bölümlerde } \\
\text { bağımsız fokus }\end{array}$ & İmmatürite & $\begin{array}{c}\text { Sol hemisfer arka } \\
\text { bölümlerde keskin } \\
\text { dalga }\end{array}$ \\
\hline $\begin{array}{l}\text { Magnetik rezonans } \\
\text { görüntüleme }\end{array}$ & $\begin{array}{l}\text { Hidrosefali, Korpus } \\
\text { Kallozum agenezisi }\end{array}$ & $\begin{array}{l}\text { Korpus Kallozum } \\
\text { hipoplazisi } \\
\text { multikistik } \\
\text { ensefalomalazi }\end{array}$ & Hidrosefali & $\begin{array}{l}\text { Korpus Kallozum } \\
\text { spleniumu ince }\end{array}$ & $\begin{array}{c}\text { Talamus } \\
\text { ve globus } \\
\text { pallidusta } \\
\text { hiperinttensite }\end{array}$ & Serebral atrofi \\
\hline $\begin{array}{l}\text { Tedavi başlama } \\
\text { yaşı }\end{array}$ & 18.gün & 35.gün & 1 yaş & 9 yaş & 7.ay & 10.ay \\
\hline Nörolojik muayene & Normal & Stereotipi & Otizm & llımlı MR & $\begin{array}{c}\text { Global gelişim } \\
\text { geriliği }\end{array}$ & Otizm \\
\hline Tedavi & B6 vitamini & B6 vitamini & B6 vitamini & $\begin{array}{l}\text { VPA, LEV, STM, } \\
\text { B6 vitamini }\end{array}$ & $\begin{array}{c}\text { VPA, CLN, B6 } \\
\text { vitamini }\end{array}$ & B6 vitamini \\
\hline \multirow[t]{2}{*}{$\begin{array}{l}\text { ALDH7A1 gene } \\
\text { mutation }\end{array}$} & $\begin{array}{c}\text { Homozigot } \\
\text { c.1597delG } \\
\text { (p.Ala533ProfsTer18) }\end{array}$ & $\begin{array}{c}\text { Homozigot } \\
\text { c.781 A>G } \\
\text { (p.Met261Val) }\end{array}$ & $\begin{array}{c}\text { Birlessik } \\
\text { heterozigot } \\
\text { c.328C>T } \\
\text { (p.Arg110Ter)/ } \\
\text { c.1566-1G>T }\end{array}$ & $\begin{array}{c}\text { Heterozigot } \\
\text { c.328C }>\mathrm{T} \\
\text { (p.Arg110Ter) }\end{array}$ & $\begin{array}{l}\text { Heterozigot } \\
\text { c.1356 A>C } \\
\text { (p.Lys452Asn) }\end{array}$ & $\begin{array}{c}\text { Homozigot } \\
\text { c.1597delG } \\
\text { (p.Ala533ProfsTer18) }\end{array}$ \\
\hline & Tanımlı & Yeni VUS & Tanımlı / Tanımlı & Tanımlı & Yeni VUS & Tanımlı \\
\hline
\end{tabular}

VPA: Valproik asit, LEV: Levetirasetam, CLN: Klonazepam, STM: Sultiam, VUS: Klinik önemi bilinmeyen

bilateral tonik-klonik, fokal nöbet, infantil spazm görülebilir, hatta status epileptikus gelișme eğilimi mevcuttur $(8,9)$. Hastalarımızın üçünde fokal motor nöbet, ikisinde jeneralize motor nöbet, birinde spazm tipinde nöbet izlenmiş olup, hiçbirinde status epileptikus gelişmedi.

Piridoksin bağımlı epilepsili hastalarda EEG normal olabileceği gibi, yüksek voltaj delta aktivitesi, fokal diken dalga deșarjları, burst-supresyon paterni ve nadiren hipsaritmi görülebilir $(10,11)$. Bizim de bir hastamızın başlangıç EEG'si normal olup, diğer hastalarımızda fokal keskin dalga deşarjları izlendi. Nörogörüntülemede, korpus kallozum hipoplazisi, posterior fossa anormallikleri (mega sisterna magna), hidrosefali, beyaz madde anormallikleri, fokal kortikal displazi, heterotopi ve nöronal migrasyon defektleri gibi çoklu beyin malformasyonları bildirilmiştir (12,13). Hastalarımızın üçünde korpus kallozum anormalliği (agenezi, hipoplazi, gövde kısmının ince olması), ikisinde hidrosefali saptandı. Mekonyumlu doğum öyküsü olan bir hastamızda multikistik ensefalomalazi, asfiktik doğum öyküsü olan diğer bir hastamızda da serebral atrofi ile uyumlu görünüm mevcuttu.

Piridoksin bağımlı epilepside klinik spektrum nöbetlerle sınırlı değildir. Birçok hastada kas tonusu değişiklikleri, irritabilite, psikomotor gerilik gibi nörolojik ișlev bozuklukları gözlenmektedir. Hastaların çoğunda hafif-orta derecede gelişimsel gerilik görülür (2). Bu semptomların, piridoksin tedavisinin geç başlanılmasına bağlı olabileceği düşünülmektedir. Bununla birlikte bazı hastalarda bu nörolojik bulgular nöbetlerin başlangıcından itibaren mevcuttur (14). Bizim hastalarımızda da eșlik eden mental retardasyon ve otizm tanıları mevcuttu. Postnatal 18. günde tedavisi bașlanan olgumuzun gelişimi normal seyretmektedir.

2000 yllinda Cormier ve ark. (15) PBE'ye neden olan genin 5q31.2 kromozomunda lokalize olduğunu bildirdiler. 2006 yllında Mills ve ark. (6) ALDH7A1 genini PBE'den sorumlu gen olarak tanımladı ve etkilenen PBE'li hastalarda mutasyon tespit ettiler. Şimdiye kadar, antiquitin (ALDH7A1) geninde birçok mutasyon tanımlanmıştır. ALDH7A1 mutasyonları missense, nonsense ve splice site mutasyonlarını içerir (16). Altı olguda 2'si yeni olmak üzere 5 farklı mutasyon saptanmıştır. Hastalarda, 2 missense, 1 nonsense, 1 splice site ve 1 delesyon tipi mutasyon saptanmıştır. PBE resesif kalııım modeli gösterse de literatürde dizi analizi ile heterozigot mutasyon saptanan, klinik olarak bulgu veren hastalarda ALDH7A1 genindeki kopya sayIsı değișikliklerinin de incelenmesi gerektiği önerilmektedir (17). Altı olgunun dördünde homozigot mutasyon saptanırken ikisinde heterozigot mutasyon saptanmiştır.

Antiquitin (ATQ) eksikliğinin standart tedavisi farmakolojik dozlarda yaşam boyu piridoksin takviyesini içerir. Optimal doz henüz tam olarak tanımlanmamıștı. Çoğu hastada, idame dozlarının çocuklarda $15-30 \mathrm{mg} / \mathrm{kg} / \mathrm{gün}$ oral yolla veya yenidoğanlarda 200 mg/gün, yetişkin hastalarda 500 mg /gün kadar olması gerektiği kabul edilmektedir (7). Tedavi sırasında, 
piridoksine gecikmiş yanıtın olabileceği ve bazen yanıtın 3-7 gün içinde alınabileceği akılda tutulmalıdır. Piridoksine yanıt vermeyen olgularda piridoksal fosfat $30-50 \mathrm{mg} / \mathrm{kg} / \mathrm{gün}$ ve folinik asit $3-5 \mathrm{mg} / \mathrm{kg} /$ gün tedaviye eklenebilir (18).

Piridoksin kullanımı ile kimyasal piridoksal fosfatın (PLP) inaktivasyonu kompanse edilirken, lizin katabolizmasından kaynaklanan substratların birikimi yeterince azalmaz. Potansiyel olaraknörotoksikolan bu bileșiklerin, iyi nöbetkontrolüne rağmen, bazı hastalarda görülen gelişimsel gecikme veya bilişsel geriliğin nedeni olabilir (19). Bu nedenle PBE'de diyette lizin kısıtlaması, lizin türevli substratların birikimini azaltabilir ve muhtemelen serebral fonksiyonun iyileşmesine katkıda bulunabilir. Yine diyete arginin eklenmesi, barsaktan lizin emilimini azaltmada yardımcı olur (20). Bazı hastalarda enfeksiyon ile nöbetler tetiklenebilir. Bu durumda piridoksin dozu üç gün süreyle iki katına $(40 \mathrm{mg} / \mathrm{kg} / \mathrm{g}$, büyük çocuklarda $500 \mathrm{mg} / \mathrm{g}$ ) artııılmalıdır. Hamilelik sırasında verilen ek piridoksin $(100 \mathrm{mg} / \mathrm{g})$ ile risk altında veya doğrulanmış PBE'li fetusun doğum öncesi tedavisi mümkündür, tedavi ile intrauterin nöbetler önlenebilir ve nörogelişimsel prognoz iyileştirilebilir $(18,20)$. Hastalarımızın dördünde sadece piridoksin tedavisi ile nöbet kontrolü sağlanırken, heterozigot mutasyon saptanan iki olguda çoklu antiepileptik tedaviye intiyaç duyuldu.

Tüm bu yeni bulgular ve literatürdeki diğer çalışmalar birlikte değerlendirildiğinde PBE'de saptanan mutasyonların oldukça heterojenite gösterdiği izlenmiştir. Literatürde daha önce tariflenmeyen c.781 A>G (p.Met261Val) ve c.1356 A>C (p.Lys452Asn) varyantları ilk defa bildirilmiştir.

Piridoksin bağımlı epilepsi tedavi edilebilir epilepsi nedenlerinden biri olup açıklanamayan dirençli nöbetleri olan bebeklerde mutlaka düşünülmeli ve terapotik dozda piridoksin tedavisine başlanmalıdır. Tanının moleküler olarak doğrulanması, yeterli genetik danışma ve erken tedavinin uygulanması için son derece önemlidir.

\section{KAYNAKLAR}

1. Hunt Ad Jr, Stokes J Jr, Mccrory Ww, Stroud Hh. Pyridoxine dependency: report of a case of intractable convulsions in an infant controlled by pyridoxine. Pediatrics 1954;13:140-5.

2. Baxter P. Pyridoxine-dependent and pyridoxine-responsive seizures. Dev Med Child Neurol 2001;43:416-20.

3. Gospe SM Jr. Pyridoxine-dependent seizures: new genetic and biochemical clues to help with diagnosis and treatment. Curr Opin Neurol 2006;19:148-53.

4. Mills PB, Footitt EJ, Mills KA, Tuschl K,Aylett S,Varadkar S, et al. Genotypic and phenotypic spectrum of pyridoxine-dependent epilepsy (ALDH7A1 deficiency). Brain 2010;133:2148-59.

5. Mills PB, Struys E, Jakobs C, Plecko B, Baxter P, Baumgartner $\mathrm{M}$, et al. Mutations in antiquitin in individuals with pyridoxinedependent seizures. Nat Med 2006;12:307-9.

6. Plecko B, Paul K, Paschke E, Stoeckler-lpsiroglu S, Struys E, Jakobs C, et al. Biochemical and molecular characterization of 18 patients with pyridoxine-dependent epilepsy and mutations of the antiquitin (ALDH7A1) gene. Hum Mutat 2007;28:19-26.
7. Stockler S, Plecko B, Gospe SM Jr. Pyridoxine dependent epilepsy and antiquitin deficiency: clinical and molecular characteristics and recommendations for diagnosis, treatment and follow-up. Mol Genet Metab 2011;104:48-60.

8. Gordon N. Pyridoxine dependency: an update. Dev Med Child Neurol 1997;39:63-5.

9. SM Gospe. Pyridoxine-dependent seizures: findings from recent studies pose new questions. Pediatr Neurol 2002;26:181-5.

10. Nabbout R, Soufflet C, Plouin P,Dulac O. Pyridoxine dependent epilepsy: a suggestive electroclinical pattern. Arch Dis Child Fetal Neonatal Ed 1999;81:125-9.

11. L. Hellstrom-Westas L, Blennow G, Rosen I. Amplitude-integrated encephalography in pyridoxine-dependent seizures and pyridoxineresponsive seizures. Acta Paediatr 2002;91:977-90.

12. Jansen LA, Hevner RF, Roden WH, Hahn SH, Jung S, Gospe SM Jr. Glial localization of antiquitin: implications for pyridoxinedependent epilepsy. Ann Neurol 2014;75:22-32.

13. Jain-Ghai S, Mishra N, Hahn C, Blaser S, Mercimek-Mahmutoglu S. Fetal onset ventriculo- megaly and subependymal cysts in a pyridoxine dependent epilepsy patient. Pediatrics 2014;133:e10926.

14. Perez B, Gonzalez L, Verdu A. Clinical, biomedical, and moleculer studies in pyridoxine-dependent epilepsy. Antisense therapy as possible new therapeutic option. Epilepsia 2013;54:239-48.

15. Cormier-Daire V, Dagoneau N, Nabbout R, Burglen L, Penet C, Soufflet C, et al. A Gene for Pyridoxine-Dependent Epilepsy Maps to Chromosome 5q31. Am J Hum Genet 2000;67: 991-3.

16. Tlili A, Hentati N, Chaabane R. Pyridoxine-dependent epilepsy in Tunisia is caused by a founder missense mutation of ALDH7A1 gene. Gene 2013; 518: 242-5.

17. Mefford HC, Zemel M, Geraghty E, Cook J, Clayton PT, Paul K, et al. Intragenic deletions of ALDH7A1 in pyridoxine-dependent epilepsy caused by Alu-Alu recombination. Neurology 2015;85:756-62.

18. Campistol J. Epilepsy in inborn errors of metabolism with therapeutic options. Semin Pediatr Neurol 2016;23:321-31.

19. Bok LA, Halbertsma FJ, Houterman S. Long-term outcome in pyridoxine-dependent epilepsy. Dev Med Child Neurol 2012;54:849-54.

20. Van Karnebeek CD, Jaggumantri S. Current treatment and management of pyridoxine-dependent epilepsy. Curr Treat Options Neurol 2015;17:335. 